\title{
The relationship between commodity types, spatial characteristics, and distance optimality of logistics facilities
}

\author{
Takanori Sakai (corresponding author) \\ Singapore-MIT Alliance for Research and \\ Technology \\ takanori@smart.mit.edu

\section{Tetsuro Hyodo} \\ Tokyo University of Marine Science and \\ Technology \\ hyodo@kaiyodai.ac.jp
}

\author{
Kazuya Kawamura \\ University of Illinois at Chicago \\ kazuya@uic.edu
}

\begin{abstract}
We analyze the relationship between the location of logistics facilities and the goods vehicle travel distances for the shipments associated with the facilities, using data from a large urban freight survey conducted in the Tokyo Metropolitan Area in 2013. Our analysis categorizes the logistics facilities into groups based on the type of commodity they handle. The analysis sheds light on the complex relationship between the location and "distance optimality gap," defined as the gap between the minimum travel distance possible and the actual distance traveled by goods vehicles. The results indicate that, while the lack of available space for logistics land use near the urban center leads to significant distance optimality gaps for some logistics facility groups, such as those handling daily goods, these same locations may not be advantageous for others. Also, the logistics facilities in the exurbs are likely to have large distance optimality gaps because these locations are often far away from the origins and destinations of their shipments. In terms of land-use policy, the study reveals that simply concentrating logistics facilities near the urban core or suburbs may not reduce truck traffic. Detailed data on logistics facilities and shipments are crucial for formulating effective approaches to improve the distance optimality of logistics land use.
\end{abstract}

Keywords: Urban freight distribution, land use, city logistics, logistics sprawl

\section{Article history:}

Received: December 17, 2017

Received in revised form:

April 2, 2018

Accepted: May 31, 2018

Available online: August 15,

2018

Copyright 2018 Takanori Sakai, Kazuya Kawamura, \& Tetsuro Hyodo

http://dx.doi.org/10.5198/jtlu.2018.1363

ISSN: 1938-7849 | Licensed under the Creative Commons Attribution - Noncommercial License 4.0

The Journal of Transport and Land Use is the official journal of the World Society for Transport and Land Use (WSTLUR) and is published and sponsored by the University of Minnesota Center for Transportation Studies. 


\section{$1 \quad$ Introduction}

The changes in the spatial distribution of logistics facilities that accompanied the evolution in logistics practices have been observed widely around the world, especially in the last one or two decades. In particular, the decentralization of logistics facilities, so called "logistics sprawl" (Dablanc \& Rakotonarivo, 2010), has been observed in many cities. It is argued that such decentralization of logistics facilities occurred due to the scarcity of available land, high land price, and traffic congestion near the urban center, in addition to the changes in the functional and physical requirements for logistics facilities (Sakai, Kawamura, \& Hyodo, 2015). While the concern about the impacts of logistics sprawl is widespread, public policies that locate logistics facilities in socially desirable locations are rarely discussed. The void can be partly attributed to the lack of detailed shipment data, which is needed to carry out the comprehensive evaluation of the logistics facility locations in term of the impacts on urban freight traffic. In other words, it is not well understood how the logistics facilities can be distributed across an urban area to reduce freight traffic and associated negative impacts. The structures of urban logistics chains are highly heterogeneous, reflecting the activities and needs of various business entities. Consequently, the spatial distribution of logistics land use also varies by the activities and the needs of business entities. To gain insights for formulating effective logistics land use policies to curb negative impacts that urban freight traffic entails, the analysis of detailed information regarding the locations and operations of logistics facilities is imperative.

The purpose of this research is to look at the logistics system performances in relation to the locations of the logistics facilities. What distinguishes the present paper from previous works is that we look at the effects of the commodity type handled by the logistics facilities. Our analysis uses a concept of "distance optimality gap" (DOG), which is a measure of the performance of logistics facility location based on the gap between the actual and optimum travel distances for the shipments to/from a facility. The optimum travel distance is the total goods vehicle distance traveled (GVDT) that can be achieved at the (hypothetical) optimum location. In other words, at the optimum location, the total GVDT for the shipments (both inbound and outbound) associated with the facility is minimized. DOG can be evaluated for a facility or for a group of facilities.

We assume that DOG can be used as the measure of the externalities associated with truck shipments since a large part of negative impacts of urban freight traffic is connected to vehicle trip distances (Richardson, 2005). It should be noted that the optimum location for a logistics facility is not necessarily "optimum" from the logistics operators' perspective. Logistics operators make decisions for logistics facility locations based on various factors such as land availability, land price, transportation system reliability, land use regulations, and the accessibilities to customers and suppliers.

While this study does not consider the total social benefit that takes into account both the internal and external costs, the detailed diagnosis of logistics systems described here should help understand the relationships among commodity types handled, locations of logistics facilities, and externalities (estimated by the DOGs). We use the data from the arguably largest urban freight survey in the world, the 2013 Tokyo Metropolitan Freight Survey (TMFS), to conduct the analysis for the study area, the Tokyo Metropolitan Area (TMA) in Japan.

The rest of the paper consists of the following sections: the review of the existing research that focuses on urban logistics facility locations and traffic impacts associated with facility locations; the description of the study area; an overview of the dataset and the analytical methodology; the discussion of the result of the analysis; and the conclusion. 


\section{$2 \quad$ Literature review}

Urban logistics land use is one of the most rapidly emerging research subjects in the field of urban freight (Taniguchi, Thompson, \& Yamada, 2016). Especially, the concept of logistics sprawl, "the spatial deconcentration of logistics facilities and distribution centers in metropolitan areas" (Dablanc \& Rakotonarivo, 2010) is widely discussed in academic literature. Outward migrations of logistics facilities have been measured and confirmed in many cities around the world, especially in North America and Europe (Cidell, 2010; Dablanc \& Rakotonarivo, 2010; Dablanc \& Ross, 2012; Dablanc, Ogilvie, \& Goodchild, 2014; Sakai et al., 2015; Sakai, Kawamura, \& Hyodo, 2017; Todesco, Weidmann, \& Haefeli, 2016; Woudsma, Jakubicek, \& Dablanc, 2016). Those literature focus on the broad trends in the spatial distributions of logistics facilities, lumping together facilities of different types, while only a few, such as Raimbault, Andriankaja, and Paffoni (2012), Heitz and Beziat (2016), and Sakai, Kawamura, and Hyodo (2016a), delve into the details of the location choices, distinguishing the logistics facilities having different characteristics.

Despite the recent publications of studies on urban freight land use and especially the logistics sprawl, research on the evaluation of the impacts of urban logistics facility locations is still very limited mainly due to data scarcity (Aljohani \& Thompson, 2016). Concerns over the negative social impacts of logistics sprawl are largely based on the assumption that facilities in the suburbs or exurbs would be far from the concentration of shipment origins and destinations in the urban center, thus increasing the shipment distances. However, only few studies have empirically examined the relationship between facility locations and shipment origins and destinations to verify such assumption. Wagner's work (2010) is notable in that it uses the origin-destination (OD) data for Hamburg, Germany, obtained from a survey and commuter statistics, to evaluate the traffic impacts of two locational patterns of logistics land use. Sakai et al. (2015) use the 2003 TMFS data and analyze the relationship between the logistics facilities' distances from the urban center and their efficiencies. While Wagner uses aggregated OD data to evaluate the hypothetical land use pattern, they use the shipment information (i.e., OD and truck trips) of each facility and evaluate the performance of their actual locations. The study by Sakai et al. (2015) and subsequent work by Sakai et al. (2017) reveal that the effects of outward migration of logistics facilities on shipment distances are far from simple and would require better understanding to formulate effective policy approaches.

The present research pushes the analysis of Sakai et al. (2015) forward, using the latest urban freight survey data, segmenting logistics facilities by type of commodities handled, and applying new analytical approaches. We use detailed and comprehensive dataset to measure DOGs of logistics facilities and obtain policy insights on desirable spatial distribution of logistics facilities at the level of detail that, to our knowledge, unprecedented.

\section{The study area: Tokyo Metropolitan Area (TMA)}

In this paper, we focus on the logistics facilities in the TMA, encompassing the area of $23 \mathrm{~km}^{2}$. The TMA is the world's most populous metropolitan area. The population and the number of establishments in the study area are 42 million (in 2010) and 1.6 million (in 2012), respectively. The urban morphology of the TMA is monocentric. As shown in Figure 1, the expressway system consists of radial and ring roads (with some missing sections), having the busiest district in the TMA at its center. In this paper, we call the center of the expressway system (and the TMA), the "urban center." The population is most concentrated around the urban center and the density declines with distance away from the urban center. Most of the high-density areas ( $\geq 5,000$ people per $\left.\mathrm{km}^{2}\right)$ are within $40 \mathrm{~km}$ from the urban center. The study area also covers the areas along the east-west expressway in the north, the Kita-Kanto 
Expressway (KKE), along which there are small population clusters. We call the core part of the TMA's urban development, areas that are approximately within $40 \mathrm{~km}$ from the urban center with minimum population density of 5,000 people per $\mathrm{km}^{2}$, "main urban cluster." On the other hand, the distant locations from the main urban cluster are called "exurb"; the area along the KKE is considered an exurb.

Sakai et al. (2015) report the outward migration of inland logistics facilities during the period 1980-2003. Their latest study (Sakai et al., 2017) also confirms that the outward of migration of logistics facilities continued between 2003 and 2013.

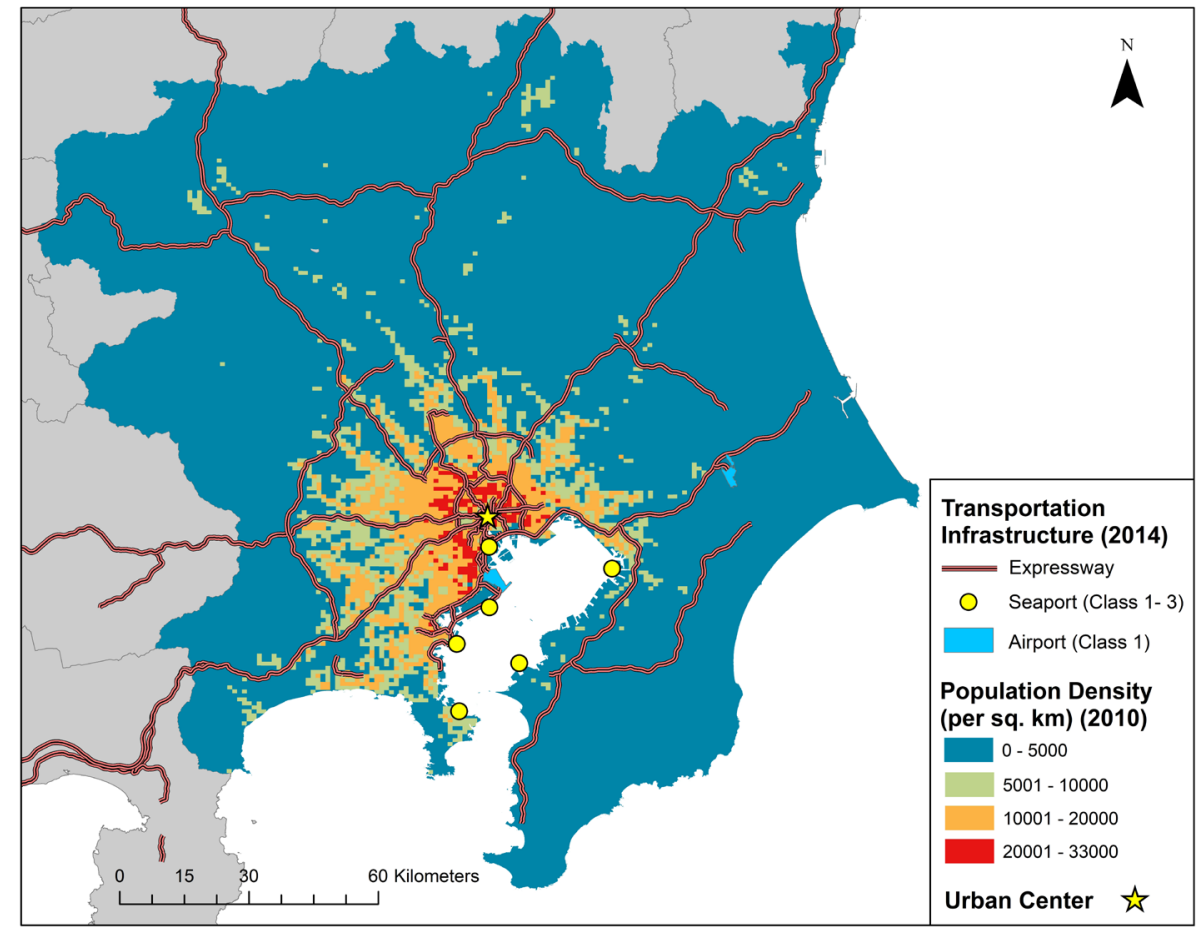

Figure 1: Transportation infrastructure and population density in the TMA

Source: Ministry of Internal Affairs and Communications, 2010; Ministry of Land, Infrastructure, Transport and Tourism, 2008, 2014a, 2014b, 2014c, visualization by authors

\section{$4 \quad$ Data and methodology}

\subsection{Data}

The main data for the analysis are the establishment-level records of logistics facilities that include distribution centers, truck terminals, warehouses, intermodal facilities and oil terminals, obtained from the 2013 TMFS. The 2013 TMFS is an urban freight establishment survey that collected data from the freight-related major entities, such as manufacturers, wholesalers, retailers, and transport service providers, in the TMA. The survey was conducted in 2013 by the Transport Planning Commission of the Tokyo Metropolitan Region (TPCTMR). Survey population was defined based on the 2009 Economic Census Data and a total of 136,632 establishments were recruited. A total of 43,131 establishments completed and returned the survey form (a response rate of $31.6 \%$ ). The survey data include 4,580 logistics facilities, of which, 2,147 facilities (11\% of all logistics facilities in the TMA) provided complete records of both inbound and outbound shipments. We use the data for those 2,147 logistics facilities varying in floor sizes $\left(\leq 300 \mathrm{~m}^{2}: 14.7 \%, 300-1,000 \mathrm{~m}^{2}: 21.0 \%, 1,000-3,000 \mathrm{~m}^{2}: 22.7 \%, 3,000-\right.$ 
$10,000 \mathrm{~m}^{2}: 24.2 \%$, and $\left.>10,000 \mathrm{~m}^{2}: 17.4 \%\right)$. The shipment records include commodity type, number of goods vehicles (including vans and trucks) used, and trip origins or destinations at the municipality level (or at the prefectural level for outside of the TMA). In this paper, we use goods vehicle trip as the unit for shipments and call each goods vehicle trip a "trip."

For comparing the logistics facilities by type of commodity handled, we categorize them into six groups based on the most frequently handled (in terms of goods vehicle trips for both inbound and outbound directions) type of commodity. Table 1 shows the commodities associated with each group. The six commodity type-based groups are foods, daily goods, raw materials, machinery, chemical goods, and mixed goods. Table 2 shows the sizes of original and expanded samples and associated trips. Of those, 35 facilities handled two types of commodity equally and therefore were counted as samples in both groups. The expansion factors based on location, type of industry, and employment size were provided by the TPCTMR. However, since the samples without either inbound or outbound shipments are excluded in our analysis, we developed another set of expansion factors based on the distance from the urban center and facility's floor area in addition to the expansion factors provided by the TPCTMR.

Table 1: Logistics facility groups based on the type of most frequently handled commodity

\begin{tabular}{ll}
\hline Group & Commodity types included \\
\hline 1. Foods & Agricultural, fish and stock farm products; food products \\
2. Daily goods & Household products; printed products; light industrial products \\
3. Raw materials & Woods; minerals; metals \\
4. Machinery & General machineries; electronic goods; transportation equipment; precision instruments \\
& and apparatus \\
5. Chemical goods & Chemical products; ceramic products \\
6. Mixed goods & Goods from more than one shippers, including parcels \\
\hline
\end{tabular}

Table 2: 2013 TMFS dataset used for the analysis

\begin{tabular}{lllll}
\hline Group & Original samples & \multicolumn{2}{l}{ Expanded samples } \\
\hline & No. of facility & $\begin{array}{l}\text { Associated trips } \\
\text { per day } \\
\text { (inbound and outbound) }\end{array}$ & No. of facility & $\begin{array}{l}\text { Associated trips } \\
\text { per day } \\
\text { (inbound and outbound) }\end{array}$ \\
\hline 1. Foods & 551 & 28,702 & 4,947 & 204,494 \\
2. Daily goods & 539 & 16,909 & 4,970 & 127,645 \\
3. Raw materials & 336 & 7,731 & 3,342 & 69,246 \\
4. Machinery & 330 & 10,453 & 2,905 & 83,516 \\
5. Chemical goods & 313 & 7,900 & 2,785 & 63,169 \\
6. Mixed goods & 113 & 7,169 & 719 & 31,634 \\
\hline
\end{tabular}

\subsection{Methodology}

The objective of the analysis is to compare the relationships between the locations of logistics facilities and the total travel distances (i.e., total GVDT) to the reported shipment origins (of inbound shipments) and destinations (of outbound shipments) at the facility and facility group levels. As stated earlier, we consider the DOG to be the proxy of the externalities associated with goods vehicle travel. 
First, we compute the "optimum location" that minimizes the total GVDT for each logistics facility, taking both inbound and outbound trips into account. The optimum location, which is specified as a network node for facility $f$, node optimum $_{\text {, }}$ is given by:

$$
\min _{\text {node }_{\text {optimum }}} \sum_{d \in D^{f}} \text { dist. }\left(\text { node }_{d}, \text { node }_{\text {f optimum }}\right)
$$

where,

$D^{f}$ : the set of all demand locations for facility $f$

node $d_{d}$ :the network node of demand location $d$

dist.(,): the shortest distance between two network nodes

To compute network-based travel distances, we use the comprehensive road network data for the TMA applying the shortest-path analysis. The shipment records include both internal and external trips. An internal trip has its origin and destination in the study area, while an external trip has either origin or destination outside of the study area. To each external trip, we assign a cordon point along the border of the study area and on the likely path of the trip. Thus, we take into account only the portion of each external trip that is within the study area. We call the origins of inbound trips and the destinations of outbound trips (or cordon points for external trips) "demand locations."

Next, for each facility group $g$ (food, daily goods, raw materials, machinery, chemical goods, or mixed goods), we calculate the "facility-based" actual average travel distance (equation 2) and optimum average travel distance (equation 3).

Actual average travel distance (facility-based) for facility group $g$ :

$$
\frac{1}{N_{F} g} \sum_{f \in F^{g}}\left(\frac{1}{N_{D^{f}}} \sum_{d \in D^{f}} \text { dist. }\left(\text { node }_{d}, \text { node }_{f} \text { actual }\right)\right)
$$

Optimum average travel distance (facility-based) for facility group $g$ :

$$
\frac{1}{N_{F} g} \sum_{f \in F g}\left(\frac{1}{N_{D} f} \sum_{d \in D^{f}} \text { dist. }\left(\text { node }_{d}, \text { node }_{f} \text { optimum }\right)\right)
$$

where,

$D^{f}$ : the set of all demand locations for facility $f$

$F^{g}$ : the set of all facilities in group $g$

$N_{F} g, \mathrm{~N}_{D}$ : the numbers of elements in $F^{g}$ and $D^{f}$, respectively

node $_{d}$ : the network node of demand location $d$

node $_{f}$ actual: the network node of the actual location of facility $f$

node optimum: the network node of the optimum location of facility $f$

dist.(,): the shortest distance between two network nodes

While the facility-based distances are averages of the mean trip distances calculated at the facility level, we also compute the "trip-based" actual average travel distance (equation 4) and optimum average travel distance (equation 5) that are (direct) averages of all the trips.

Actual average travel distance (trip-based) for facility group $g$ :

$$
\frac{1}{N_{D^{F}} g} \sum_{d \in D^{F}} \text { dist. }\left(\text { node }_{d}, \text { node }_{\text {f actual }}\right)
$$


Optimum average travel distance (trip-based) for facility group $g$ :

$\frac{1}{N_{D^{F}} g} \sum_{d \in D^{F}}$ dist. $\left(\right.$ node $_{d}$, node $\left._{\text {f optimum }}\right)$

where,

$D^{F^{g}}$ : the set of all demands for facilities in group $g$

$N_{D}{ }^{F^{g}}$ : the number of elements in $D^{F^{g}}$

node $_{d}$ the network node of demand location $d$

node $_{f}$ actual: the network node of the actual location of facility $f$

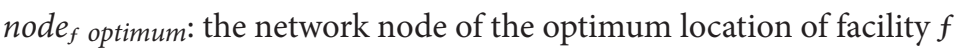

dist.(,): the shortest distance between two network nodes

The gap (in difference or in ratio) between the actual and the optimum average travel distances (either facility-based or trip-based) represents the overall DOG for each facility group, which we will call "group DOG" hereafter.

In addition to the above-mentioned indicators, we also compute the difference between the actual and optimum average travel distances for each facility (called "facility-specific DOG" hereafter), which is given by the following equation:

$\frac{1}{N_{D f}} \sum_{d \in D} f\left(\right.$ dist. $\left(\right.$ node $_{d}$, node $\left._{\text {f actual }}\right)-\operatorname{dist.}\left(\right.$ node $_{d}$, node $\left.\left._{\text {optimum }}\right)\right)$

where,

$D^{f}$ : the set of all demand locations for facility $f$

$N_{D^{f}}$ : the numbers of elements in $D^{f}$

node $_{d}$ : the network node of demand location $\mathrm{d}$

node $_{\text {actual: }}$ the network node of the actual location of facility $f$

node $e_{\text {optimum: }}$ the network node of the optimum location of facility $f$

dist.(,): the shortest distance between two network nodes

We compare the DOGs of different logistics facilities or facility groups, using the indicators defined above, and analyze the sources of the differences.

\section{$5 \quad$ Results}

\subsection{Distance from the urban center and group DOGs}

We begin the analysis by examining the actual and optimum logistics facility locations in relation to the urban center. Table 3 compares the average distances from the urban center for different groups. The facilities handling foods and chemical goods are relatively far from the urban center as a whole ( $44.8 \mathrm{~km}$ and $47.5 \mathrm{~km}$, respectively), while those handling daily goods are closest to the urban center $(33.0 \mathrm{~km})$. The comparison of actual and optimum locations indicates that the difference in the distances from the urban center is the greatest for the facilities that handle foods $(+5.4 \mathrm{~km})$, while the smallest for those handling daily goods $(-0.6 \mathrm{~km})$. Surprisingly, the facilities that mainly handle daily goods are located slightly closer to the urban center than their optimum locations.

On the other hand, as Table 4 shows, facility-based average travel distance is the shortest for the facilities that handle mixed goods $(27.7 \mathrm{~km})$, which is also the closest $(+5.6 \mathrm{~km})$ to the average travel distance for the optimum locations. On the other hand, the difference in the average travel distances 
between the actual and optimum locations is the greatest for those handling daily goods $(+10.5 \mathrm{~km})$, despite their closeness to the urban center. These results, shown in Table 3 and Table 4, suggest that the distance from the urban center is not the only determinant of the group DOG, and commodity being handled plays a role.

However, when the trip-based figures are examined (Table 5), a slightly different picture emerges. The ratio between the actual and optimum average travel distances (trip-based) is the highest for those handling mixed goods (1.33), indicating a large group DOG. The table also shows that the trip-based average travel distance is the shortest for the logistics facilities handling mixed goods; however, it is $20 \%$ longer than the facility-based average distance (column e in Table 5). One of the reasons for this is that at the facilities handling mixed goods, more goods vehicle trips are generated by longer supply chains; this is indicated by column $\mathrm{f}$ in Table 5; the optimum trip-based average travel distance is $13 \%$ longer than the facility-based average travel distance (since the facility-based figure does not reflect the effect of variation in the numbers of trips associated with facilities). Another reason is that the facilities with large facility-specific DOGs tend to have greater number of goods vehicle trips associated with them than the ones with small DOGs, which is inferred by the greater value of column e than column $\mathrm{f}$ in Table 5 (1.20 and 1.13).

Interestingly, the value of column e exceeds that of column $\mathrm{f}$ only for the mixed goods-handling facilities. For other groups, the values of column e are smaller, indicating that the facilities with small facility-specific DOGs tend to be used more than those with large DOGs. The locations of the facilities that handle mixed goods are relatively close to their optimum locations but the use (i.e., the number of associated goods vehicle trips) is more concentrated in the facilities with large facility-specific DOGs. Consequently, logistics operations for mixed goods produce longer trips than those expected from the facility locations. These results underline the importance of data on the throughput volumes for evaluating the performance of logistics system, especially for those handling mixed goods.

Lastly, Table 6 shows the total differences between actual and optimum travel distances by facility group. Although the logistics facilities handling mixed goods show a large group DOG based on the trip-based travel distance, their contribution to the overall DOG of the entire logistics facility system is only $6.0 \%$ because of the small number of shipments associated with them. The largest contribution to the difference is made by the facilities that handle foods $(31.1 \%)$, followed by those handling daily goods $(26.5 \%)$.

Table 3: Actual and optimum distances from the urban center

\begin{tabular}{|c|c|c|c|c|}
\hline \multirow[t]{2}{*}{ Group } & \multicolumn{2}{|c|}{ Ave. dist. from urban center $(\mathrm{km})$} & \multirow{2}{*}{$\begin{array}{l}\text { c. Difference }(\mathrm{km}) \\
(\mathrm{a}-\mathrm{b})\end{array}$} & \multirow{2}{*}{$\begin{array}{l}\text { d. Ratio } \\
(\mathrm{a} / \mathrm{b})\end{array}$} \\
\hline & a. at actual location & b. at optimum location & & \\
\hline 1. Foods & 44.8 & 39.3 & 5.4 & 1.14 \\
\hline 2. Daily goods & 33.0 & 33.6 & -0.6 & 0.98 \\
\hline 3. Raw materials & 40.1 & 37.9 & 2.2 & 1.06 \\
\hline 4. Machinery & 38.8 & 37.1 & 1.8 & 1.05 \\
\hline 5. Chemical goods & 47.5 & 45.7 & 1.8 & 1.04 \\
\hline 6. Mixed goods & 39.3 & 36.7 & 2.5 & 1.07 \\
\hline
\end{tabular}


Table 4: Travel distances (facility-based)

\begin{tabular}{|c|c|c|c|c|}
\hline \multirow[t]{2}{*}{ Group } & \multicolumn{2}{|c|}{ Ave. travel dist. (facility-based) (km) } & \multirow{2}{*}{$\begin{array}{l}\text { c. Difference }(\mathrm{km}) \\
(\mathrm{a}-\mathrm{b})\end{array}$} & \multirow{2}{*}{$\begin{array}{l}\text { d. Ratio } \\
(\mathrm{a} / \mathrm{b})\end{array}$} \\
\hline & a. Actual & b. Optimum & & \\
\hline 1. Foods & 39.2 & 30.9 & 8.3 & 1.27 \\
\hline 2. Daily goods & 40.6 & 30.0 & 10.5 & 1.35 \\
\hline 3. Raw materials & 37.0 & 29.4 & 7.6 & 1.26 \\
\hline 4. Machinery & 45.7 & 36.5 & 9.2 & 1.25 \\
\hline 5. Chemical goods & 40.5 & 32.4 & 8.0 & 1.25 \\
\hline 6. Mixed goods & 27.7 & 22.1 & 5.6 & 1.26 \\
\hline
\end{tabular}

Table 5: Travel distances (trip-based)

\begin{tabular}{|c|c|c|c|c|c|c|}
\hline Group & $\begin{array}{l}\text { Ave. trave } \\
\text { (trip-base } \\
\text { a. Actual }\end{array}$ & $\begin{array}{l}\text { istance } \\
(\mathrm{km}) \\
\text { b. Optimum }\end{array}$ & $\begin{array}{l}\text { c. } \\
\text { Difference } \\
(\mathrm{km})(\mathrm{a}-\mathrm{b})\end{array}$ & $\begin{array}{l}\text { d. } \\
\text { Ratio } \\
(\mathrm{a} / \mathrm{b})\end{array}$ & $\begin{array}{l}\text { e. Ratio of } \\
\text { actual ave. } \\
\text { travel dist. } \\
\text { (trip-based/ } \\
\text { facility-based) }\end{array}$ & $\begin{array}{l}\text { f. Ratio of } \\
\text { optimum ave. } \\
\text { travel dist. } \\
\text { (trip-based/ } \\
\text { facility based) }\end{array}$ \\
\hline 1. Foods & 37.1 & 30.4 & 6.6 & 1.22 & 0.95 & 0.99 \\
\hline 2. Daily goods & 45.2 & 36.2 & 9.0 & 1.25 & 1.11 & 1.20 \\
\hline 3. Raw materials & 42.4 & 35.1 & 7.3 & 1.21 & 1.15 & 1.19 \\
\hline 4. Machinery & 51.0 & 43.5 & 7.5 & 1.17 & 1.12 & 1.19 \\
\hline 5. Chemical goods & 42.7 & 35.5 & 7.2 & 1.20 & 1.06 & 1.09 \\
\hline 6. Mixed goods & 33.2 & 24.9 & 8.3 & 1.33 & 1.20 & 1.13 \\
\hline
\end{tabular}

Table 6: Total difference between the actual and optimum travel distances by facility group

\begin{tabular}{|c|c|c|c|c|c|c|c|}
\hline & \multicolumn{6}{|l|}{ Group } & \multirow[t]{3}{*}{ All } \\
\hline & 1. & 2. & 3. & 4. & 5. & 6 & \\
\hline & Foods & Daily goods & Raw materials & Machinery & Chemical goods & Mixed goods & \\
\hline $\begin{array}{l}\text { Difference between } \\
\text { the total actual and } \\
\text { optimum travel } \\
\text { distances } \\
\text { (thou. vehicle-km) }\end{array}$ & 1,355 & 1,151 & 505 & 622 & 456 & 262 & 4,352 \\
\hline Share (\%) & 31.1 & 26.5 & 11.6 & 14.3 & 10.5 & 6.0 & 100.0 \\
\hline
\end{tabular}

\subsection{The locations of logistics facilities and facility-specific DOGs}

This section examines, using the maps, the relationship between the facility-specific DOGs and the locations of logistic facilities. The facility-specific DOGs are depicted based on actual (Figure 2) and optimum (Figure 3) logistics facility locations for the 2,147 samples at the network node level. There are two sizes of dots in the figures. The larger dots indicate the facilities for which the DOGs are $30 \mathrm{~km}$ or greater, and the following discussions focus on those facilities. The comparison between Figure 2 and Figure 3 sheds light on the details of the problems associated with the locations of logistics facilities in the TMA. We start the discussion with the logistics facilities that handle daily goods and mixed goods, 
the groups that show the greatest group DOGs in terms of trip-based average travel distances.

As discussed earlier, the average distance from the urban center is the shortest for the logistics facilities handling daily goods. Of those, the facilities with large DOGs (30 km or larger) are widely scattered around the TMA, while their optimum locations are tightly concentrated near the urban center. At the same time, some of the facilities that are located relatively close to the urban center have large DOGs. Some of the facilities with large DOGs mostly handle external trips, and for them, optimum locations are near the border of the study area (see Figure 3). Yet, when the actual locations are analyzed, they turned out to be quite far from the border, even near the urban center in some cases, resulting in large DOGs.

The facilities handling mixed goods with large DOGs are mainly located in the northern exurb of the TMA (seven out of nine facilities before sample expansion). The optimum locations for most of these facilities are within or adjacent to the main urban cluster and are not necessarily close to the urban center. This suggests that the high throughput volumes of the facilities with large DOGs in the exurb are contributing significantly to the group DOG of this facility group.

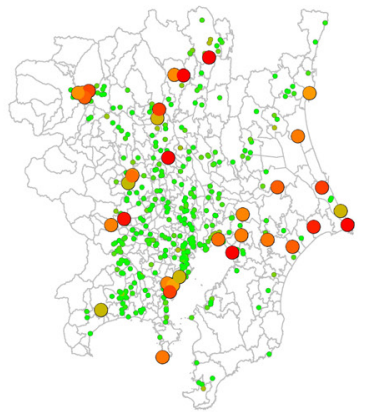

Foods

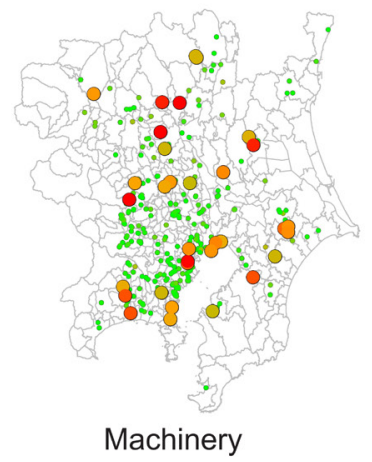

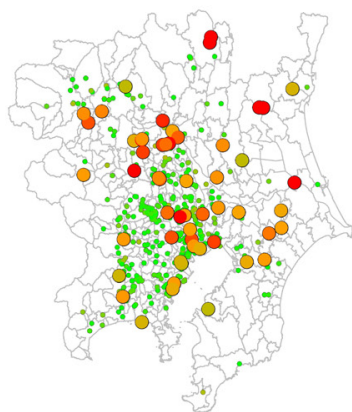

Daily goods

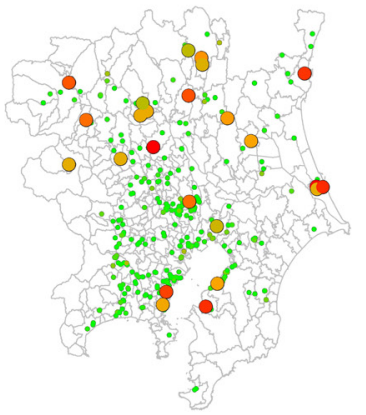

Chemical goods

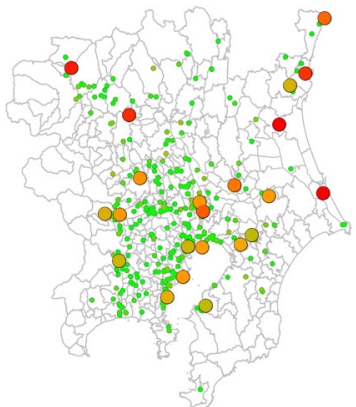

Raw materials

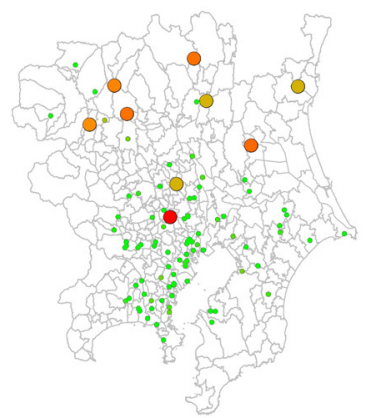

Mixed goods

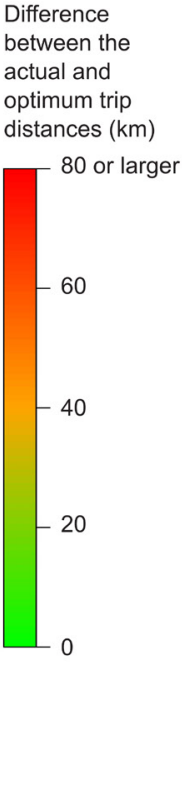

Figure 2: Facility-specific distance optimality gap (DOG) depicted at actual locations 


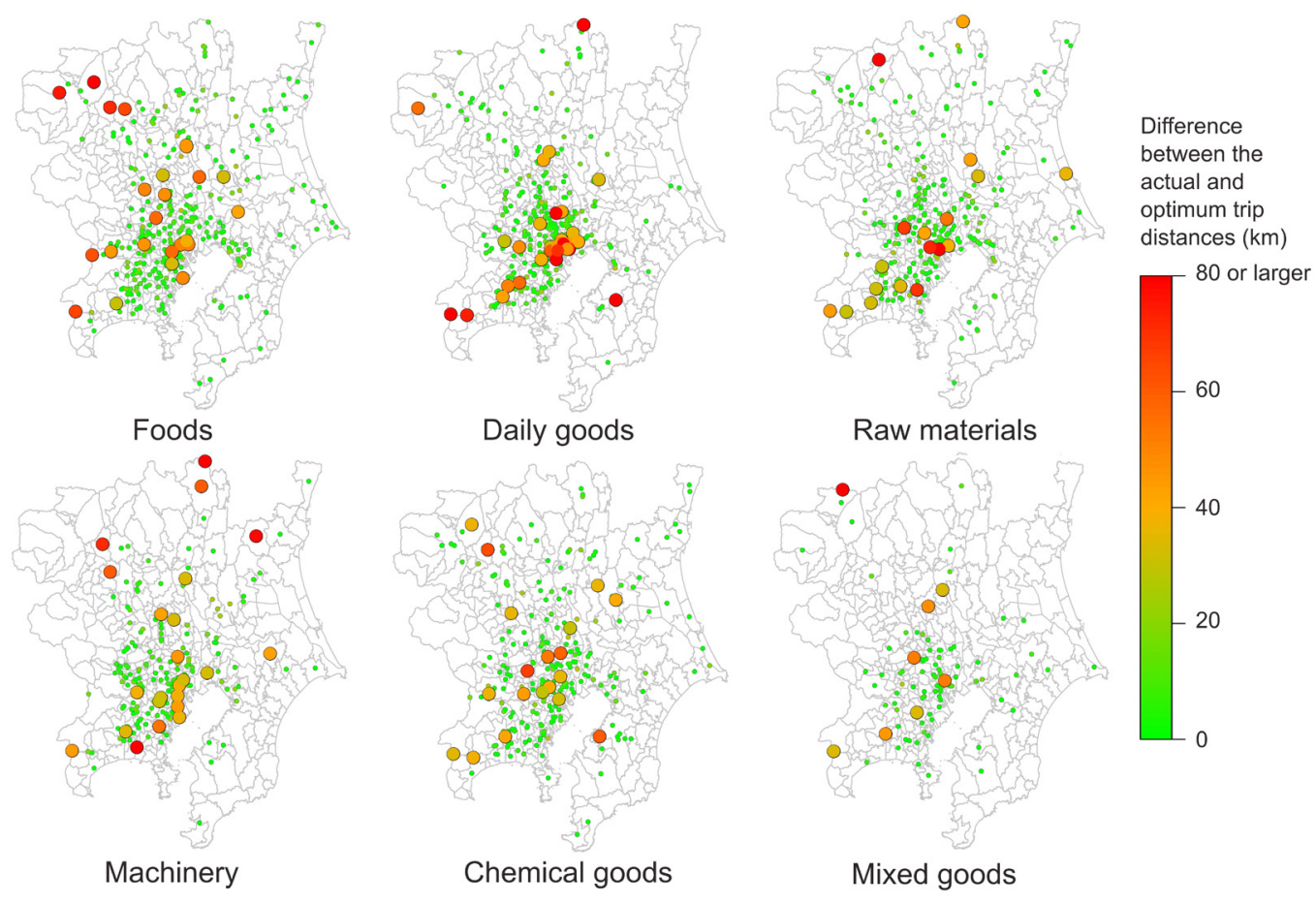

Figure 3: Facility-specific distance optimality gap (DOG) depicted at optimum locations

Figure 3 shows that the optimum locations of the facilities that handle foods and machinery with large DOGs are weakly concentrated around the urban center. In contrast, the optimum locations of the large-DOG facilities that handle raw materials and chemical goods are not necessarily concentrated around the urban center, although those located in the northern exurb of the TMA tend to show large DOGs.

Though it is difficult to generalize due to the heterogeneity within each facility group, the figures seem to indicate that when the facilities handling foods, daily goods, and machinery are located in the periphery or outside of the main urban cluster (for whatever the reason), their DOGs increase considerably. Furthermore, locations in the exurb (especially the northern part of the TMA) tend to be associated with large DOGs regardless of the type of commodity handled.

It should be noted that some facilities are far away from the optimum locations because they are located close to the origins of inbound trips, which are often the site of production (i.e., factories and farms). Even if the number of outbound trips is considerably greater than inbound trips, a location close to the production site could be more desirable for operational reasons or other reasons such as land use regulation or opposition from the community.

\subsection{The sizes of logistics facilities and group DOGs with size-based breakdown}

Next, we look at the relationship between facility size and the DOG to investigate if there is a tradeoff between the two. Our base hypothesis is that only a small number of potential sites are available for developing a larger facility, and the factors other than travel distance, such as land price and local congestion, become more critical for the businesses when selecting a site for a large facility compared to smaller ones. If this hypothesis is correct, large facilities in general should be prone to large facility-spe- 
cific DOGs than smaller counterparts. Table 7 shows the size distribution and the facility-based group DOGs with size-based breakdown. The facilities that handle food and daily goods have larger floor areas than the other facility groups, indicated by the greater shares of the facilities with floor space above 3,000 $\mathrm{m}^{2}$, while the facilities in the raw materials group tend to be relatively small.

The relationship between size and DOGs greatly varies across facility groups. For the facilities that handle foods, there is no clear correlation between size and the DOGs. It is surprising that very large food-handling facilities $\left(>10,000 \mathrm{~m}^{2}\right)$ are in locations with relatively small DOGs for this group. This is partly because some of those very large facilities are situated in the industrial zones near the major seaports in the TMA, which tend to have small DOGs.

For the other facility groups, the DOGs vary by floor area to some extent. As for the daily goods group, larger facilities tend to have greater DOGs on average. Together with the finding previously described in section 5.2 that many facilities with large facility-specific DOGs have their optimum locations near the urban center, the lack of the available (or adequate) spaces near the urban center can at least partially explain the large group DOG for the daily goods facility group. A similar, albeit more moderate, trend can be observed for other facility groups except for the mixed-goods group. On average, very large facilities, $>10,000 \mathrm{~m}^{2}$, in the mixed goods group show extremely large DOG $(19.4 \mathrm{~km})$ while smaller facilities $\left(<10,000 \mathrm{~m}^{2}\right)$ show much smaller DOGs-less than the facilities of same sizes in the other groups (except for the raw materials group in the 1,000-3,000 $\mathrm{m}^{2}$ range). This result implies that the locations of those very large facilities are not strongly guided by the travel distance, despite the fact that their optimum locations are often not next to the urban center, but in some cases, even close to the border.

Table 7: Size distribution and the average difference between the actual and optimum travel distances

\begin{tabular}{|c|c|c|c|c|c|c|c|}
\hline & & \multicolumn{6}{|l|}{ Group } \\
\hline & & 1. & 2. & 3. & 4. & 5. & 6. \\
\hline & & Foods & Daily & Raw & Machinery & Chemical & Mixed \\
\hline & Floor area $\left(\mathrm{m}^{2}\right)$ & & goods & materials & & goods & goods \\
\hline \multirow[t]{5}{*}{ No. of facility (\%) } & $\leq 300$ & 19.7 & 23.8 & 33.2 & 18.2 & 31.3 & 21.9 \\
\hline & $300-1,000$ & 21.7 & 25.8 & 25.1 & 26.1 & 29.4 & 32.5 \\
\hline & $1,000-3,000$ & 21.5 & 18.0 & 24.6 & 26.1 & 16.9 & 17.6 \\
\hline & $3,000-10,000$ & 22.6 & 19.0 & 9.4 & 18.8 & 14.4 & 19.9 \\
\hline & $>10,000$ & 14.4 & 13.3 & 7.7 & 10.7 & 8.1 & 8.1 \\
\hline Ave. difference & $\leq 300$ & 9.8 & 9.5 & 7.6 & 10.6 & 7.3 & 2.7 \\
\hline between the actual & $300-1,000$ & 8.0 & 9.1 & 10.0 & 9.0 & 6.7 & 6.1 \\
\hline and optimum travel & $1,000-3,000$ & 10.7 & 10.7 & 7.1 & 8.7 & 8.6 & 8.3 \\
\hline distances (facility- & $3,000-10,000$ & 9.3 & 14.3 & 10.6 & 12.9 & 9.3 & 5.3 \\
\hline based) (km) & $>10,000$ & 8.4 & 14.0 & 11.0 & 13.5 & 12.2 & 19.4 \\
\hline
\end{tabular}

\subsection{Contribution of the facilities with large facility-specific DOGs to group DOGs}

As noted earlier, the mixed goods facilities with large facility-specific DOGs tend to have high throughput volumes, contributing disproportionally to the trip-based group DOG. In this section, we explore whether the similar trend can be observed for other facility groups. Figure 4 illustrates how the facilities in different DOG spectrums contribute to the trip-based group DOGs. The $\mathrm{x}$-axes represent the facilityspecific DOG, i.e., the difference between the actual and optimum travel distances calculated at the facility level, in $10 \mathrm{~km}$ increments. The red bars show the contribution of the facilities to the trip-based group DOG measure, i.e., the group total of the differences between the actual and optimum travel 
distances. The blue bar in each chart shows the share of the number of logistics facilities. For example, for the foods group, about $75 \%$ of the facilities have a DOG value of 0 to $10 \mathrm{~km}$, and those facilities account for about $37 \%$ of the group DOG. On the other hand, for the mixed goods group, while the number of the facilities in the $0-10 \mathrm{~km}$ DOG is similar at around $76 \%$ of the total, they account for less than $20 \%$ of the group DOG.

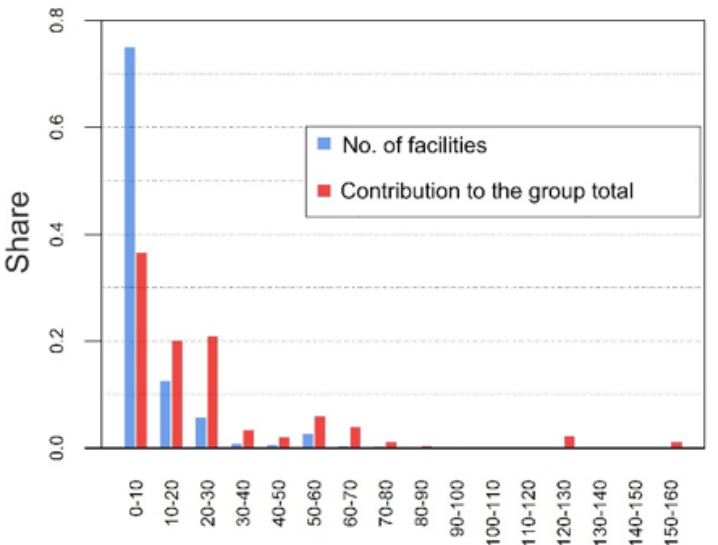

Difference between the actual and optimum travel distances $(\mathrm{km})$ Foods

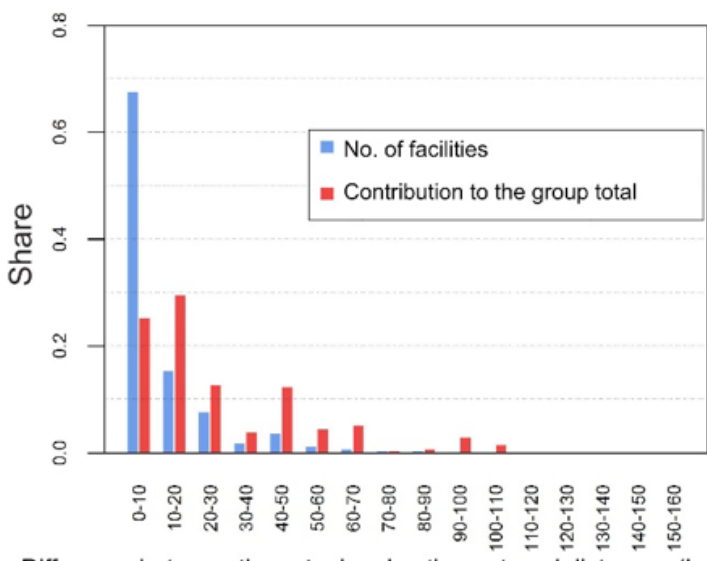

Difference between the actual and optimum travel distances $(\mathrm{km})$

Daily goods

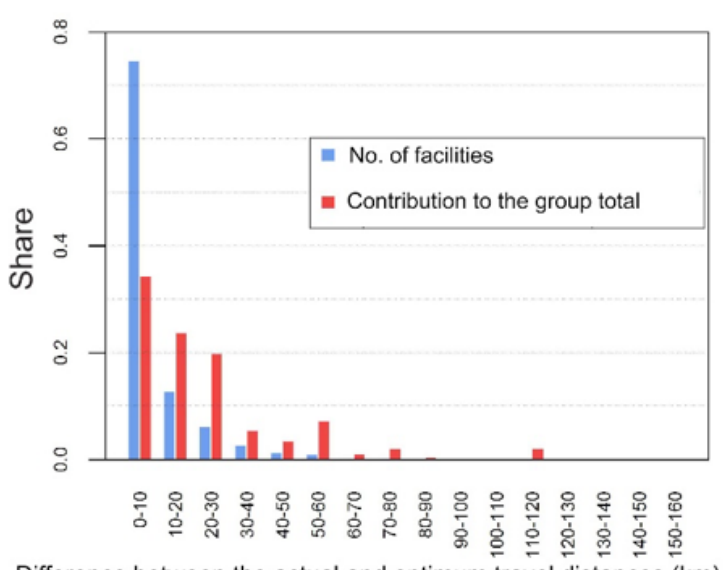

Difference between the actual and optimum travel distances $(\mathrm{km})$

Raw materials

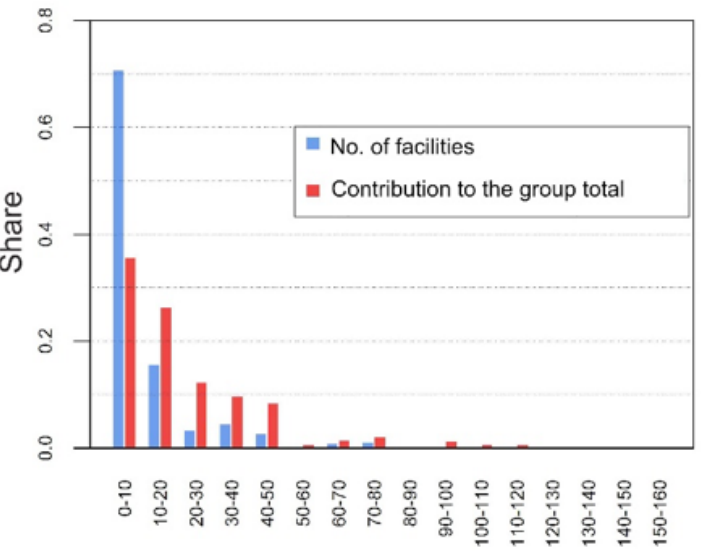

Difference between the actual and optimum travel distances $(\mathrm{km})$ Machinery

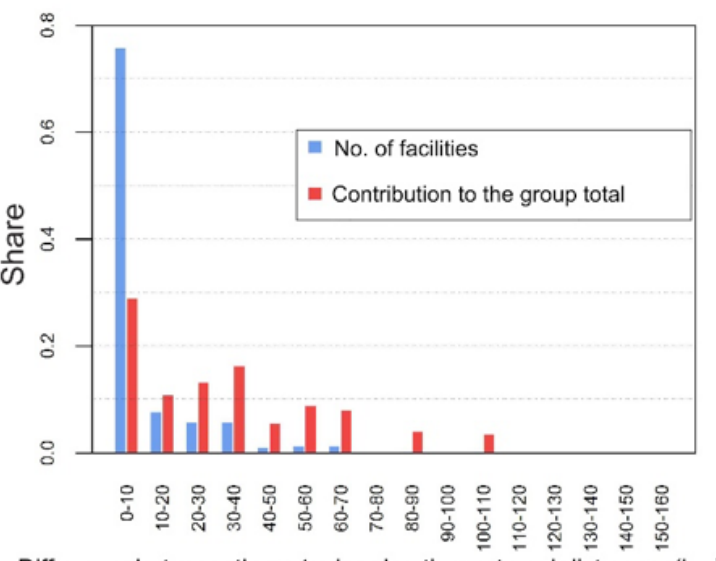

Difference between the actual and optimum travel distances $(\mathrm{km})$

Chemical goods

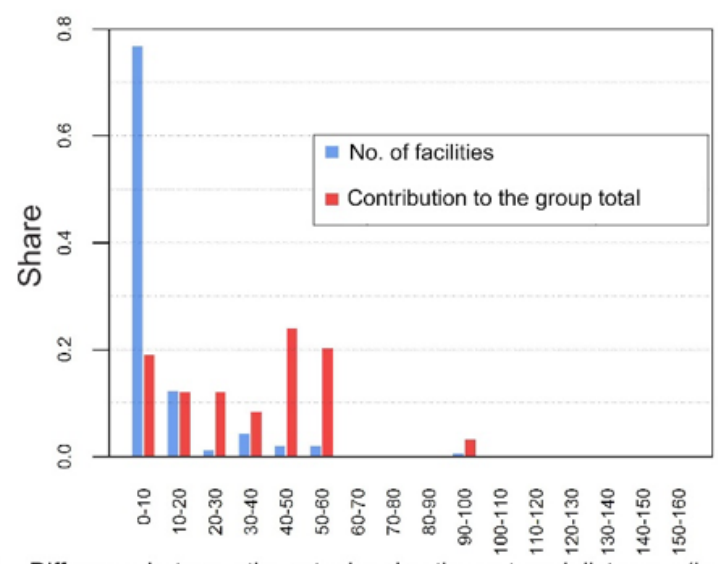

Difference between the actual and optimum travel distances $(\mathrm{km})$

Mixed goods

Figure 4: The contribution to the group total difference between the actual and optimum travel distances by the facility-specific distance optimality gap (DOG) 
In general, except for the facilities that handle mixed goods, contributions of the facilities with relatively small DOGs (close to the Y-axis) to the group DOG are high, because those facilities tend to handle the bulk of the shipments in the group. Although the facilities with very large DOGs do exist, such facilities generally handle relatively small shares of all shipments. Especially, for the facilities that handle foods, those with the DOGs of $30 \mathrm{~km}$ or more account for only $6.2 \%$ of the group DOG. Meanwhile, as for the logistics facilities that handle mixed goods, the contribution of the facilities with very large DOGs of $30 \mathrm{~km}$ or more to the group DOG is $56 \%$, although they account for only $9 \%$ of all facilities in the group. It should be noted that this analysis does not consider other aspects, for example, the relationship between locations and average load per goods vehicle; if the relocation of a facility entails a decrease in average load, then the increase in goods vehicle trips may negate the effect of the shorter trip distance.

\section{Conclusion}

Taking advantage of a rich urban freight dataset for Tokyo, we carried out detailed analyses of DOGs of the logistics facilities in the TMA by main commodity type handled. The analysis underscores the importance of recognizing heterogeneity in the relationships between spatial distribution and DOGs of logistics facilities that depend significantly on the commodities they handle. While the data show there are distinct trends in the location choices, more specifically the level of decentralization, by the commodity handled, the spatial distribution pattern in itself may provide only limited information on their DOGs. For example, despite locating relatively close to the urban center, the group DOG for the logistics facilities handling daily goods are fairly large relative to other groups of facilities. Furthermore, our analysis points to the importance of considering throughputs, as well as shipment origins and destinations, for each facility for accurately evaluating the group DOGs. For example, among the facilities handling mixed goods, a considerable share of goods vehicle trips are generated by the facilities with large DOGs, which makes the group DOG one of the greatest.

Furthermore, the analysis described in this paper underscores the fact that optimum locations (in terms of minimizing travel distances) differ across the types of commodity that logistics facilities handle. Our analysis shows that some types of logistics facilities can significantly improve the DOGs by locating near the urban center, while others may not. Also, the analysis indicates that, in most cases, the logistics facilities located in the exurb tend to have large DOGs regardless of commodities they handle. Those locations are still chosen due to the ease of acquiring a large site and/or other factors such as land price, the level of traffic and land use regulations, as pointed by the past studies (Sakai et al., 2016a; Sakai, Kawamura, \& Hyodo, 2016b). It is not clear if locating logistics facilities in the exurbs is socially beneficial or not because the benefits to the businesses for locating there can outweigh the increase in total GVDT. However, it is more than likely that businesses would prefer other locations with lower total GVDT that also satisfy other conditions if such sites are available. It should be noted that the industrial areas along the Tokyo Bay have provided such sites, i.e., large and close to the urban center, for many decades. In fact, as described in section 5.3, large food-handling logistics facilities in the Tokyo Bay industrial areas have small DOGs. As the supply of such sites dwindled and prices increased, more and more facilities started appearing in the exurbs.

While Sakai et al. (2015) advocates for flexible land use regulations to create and preserve available sites for logistics facilities, including those along the Tokyo Bay, this study shows that commodity types must also be considered when formulating actual policies. The far-reaching lesson of this study is the importance of collecting and analyzing detailed data, i.e., shipment origins, destinations and throughputs, to understand the heterogeneity associated with urban freight movements. As such, the need for 
further efforts in data collection cannot be overemphasized for developing and implementing effective logistics land use policies. One of the difficulties of designing actual policy is attributable to the fact that the demands change rapidly and frequently, and public sector has very few tools to monitor the logistics facilities and their trips constantly and precisely. Further innovations in technologies, operations, and policy development are needed in addition to further accumulation of the research on logistics facility locations and the impacts of the associated trips.

\section{Acknowledgements}

We would like to thank the Transport Planning Commission of the Tokyo Metropolitan Region for sharing the data for this research. This study received funding from the Department of Urban Planning and Policy at the University of Illinois at Chicago. 


\section{References}

Aljohani, K., \& Thompson, R. G. (2016). Impacts of logistics sprawl on the urban environment and logistics: Taxonomy and review of literature. Journal of Transport Geography, 57, 255-263.

Cidell, J. (2010). Concentration and decentralization: The new geography of freight distribution in US metropolitan areas. Journal of Transport Geography, 18(3), 363-371.

Dablanc, L., \& Rakotonarivo, D. (2010). The impacts of logistics sprawl: How does the location of parcel transport terminals affect the energy efficiency of goods' movements in Paris and what can we do about it? Procedia-Social and Behavioral Sciences, 2(3), 6087-76096.

Dablanc, L., \& Ross, C. (2012). Atlanta: A mega logistics center in the Piedmont Atlantic Megaregion (PAM). Journal of Transport Geography, 24, 432-442.

Dablanc, L., Ogilvie, S., \& Goodchild, A. (2014). Logistics sprawl: Differential warehousing development patterns in Los Angeles, California, and Seattle, Washington. Transportation Research Record: Journal of the Transportation Research Board, 2410, 105-112.

Heitz, A., \& Beziat, A. (2016). The parcel industry in the spatial organization of logistics activities in the Paris Region: Inherited spatial patterns and innovations in urban logistics systems. Transportation Research Procedia, 12, 812-824.

Ministry of Internal Affairs and Communications. (2010). National census. Retrieved from http://estat.go.jp/SG2/eStatGIS/page/download.html.

Ministry of Land, Infrastructure, Transport and Tourism. (2008). National land numerical information (port). Retrieved from http://nlftp.mlit.go.jp/ksj/gml/datalist/KsjTmplt-C02.html.

Ministry of Land, Infrastructure, Transport and Tourism. (2014a). National land numerical information (administrative zones). Retrieved from http://nlftp.mlit.go.jp/ksj/gml/datalist/KsjTmplt-N03. html.

Ministry of Land, Infrastructure, Transport and Tourism. (2014b). National land numerical information (airport). Retrieved from http://nlftp.mlit.go.jp/ksj/gml/datalist/KsjTmplt-C28-v2_3.html.

Ministry of Land, Infrastructure, Transport and Tourism. (2014c). National land numerical information (expressway time-series). Retrieved from http://nlftp.mlit.go.jp/ksj/gml/datalist/KsjTmplt-N06v1_1.html.

Raimbault, N., Andriankaja, D., \& Paffoni, E. (2012). Understanding the diversity of logistics facilities in the Paris region. Procedia-Social and Behavioral Sciences, 39, 543-555.

Richardson, B. C. (2005). Sustainable transport: Analysis frameworks. Journal of Transport Geography, 13(1), 29-39.

Sakai, T., Kawamura, K., \& Hyodo, T. (2015). Locational dynamics of logistics facilities: Evidence from Tokyo. Journal of Transport Geography, 46, 10-19.

Sakai, T., Kawamura, K., \& Hyodo, T. (2016a). Location choice models of urban logistics facilities and the impact of zoning on their spatial distribution and efficiency. Paper presented at the 95th Annual Meeting of the Transportation Research Board, Washington DC.

Sakai, T., Kawamura, K., \& Hyodo, T. (2016b). Logistics facility distribution in Tokyo Metropolitan Area: Experiences and policy lessons. Transportation Research Procedia, 12, 263-277.

Sakai, T., Kawamura, K., \& Hyodo, T. (2017). Spatial reorganization of urban logistics system and its impacts: Case of Tokyo. Journal of Transport Geography, 60, 110-118.

Taniguchi, E., Thompson, R. G., \& Yamada, T. (2016). New opportunities and challenges for city logistics. Transportation Research Procedia, 12, 5-13.

Todesco, P., Weidmann, U., \& Haefeli, U. (2016). Logistics sprawl in the Region Zurich. Paper presented at the 16th Swiss Transport Research Conference. Monte Verità, Ascona, Switzerland. 
Wagner, T. (2010). Regional traffic impacts of logistics-related land use. Transport Policy, 17(4), 224 229.

Woudsma, C., Jakubicek, P., \& Dablanc, L. (2016). Logistics sprawl in North America: Methodological issues and a case study in Toronto. Transportation Research Procedia, 12, 474-488. 